\title{
DESIGN AND FABRICATION OF MICRONOZZLES
}

\author{
K.H. CHEAH AND J.K. CHIN \\ Department of Chemical and Environmental Engineering, \\ University of Notitngham - Malaysia Campus, \\ Jalan Broga, 43500 Semenyih, Selangor Darul Ehsan, Malaysia. \\ E-mails: Jit-Kai.Chin@nottingham.edu.my,Cheah.Keanhow@nottingham.edu.my
}

ABSTRACT: Micronozzle, a key component in micropropulsion system, has been designed and fabricated. Quasi 1D inviscid theory was used in designing a series of conical micronozzles of different expander half-angles $\left(10^{\circ}-50^{\circ}\right)$. Aerospike micronozzle, a promising candidate to achieve high performance propulsion system, was designed with Angelino method (or Approximate method). Both micronozzles were fabricated using soft lithography, an inexpensive and relatively simple technique comparing to well-established deep reactive ion etching (DRIE) technique, with polydimethylsiloxane (PDMS) as structural material. Micronozzles with two different nozzle throat width, $53.5 \mu \mathrm{m}$ and $107 \mu \mathrm{m}$, were fabricated for comparison. Microscopic inspections reveal $107 \mu \mathrm{m}$ is the more producible nozzle throat width with current equipments. The PDMS-based micronozzle can be used as cold gas microthruster system for micro- and nanosatellites.

ABSTRAK: Mikronozzle, satu komponen kunci dalam sistem pendorongan-mikro telah direkabentuk and dibina. Teori quasi 1D inviscid telah digunakan dalam perekaan beberapa siri conical micronozzles dengan expander sudut-separa yang berbeza $\left(10^{\circ}\right.$ $50^{\circ}$ ). Aerospike micronozzle, calon yang menjanjikan pencapaian prestasi tinggi untuk sistem dorongan telah direkabentuk dengan menggunakan Angelino method (atau Approximate method). Kedua-dua micronozzles tersebut telah dibuat dengan menggunakan soft lithography, suatu teknik yang relatif murah and senang, dengan polydimethylsiloxane (PDMS) sebagai bahan struktur. Micronozzles dengan dua dimensi nozzle throat yang berbeza, $53.5 \mu \mathrm{m}$ and $107 \mu \mathrm{m}$, telah dibuat untuk perbandingan. Pemeriksaan mikroskopik mendedahkan bahawa $107 \mu \mathrm{m}$ adalah dimensi yang boleh dibuat dengan peralataan yang sedia ada.

KEY WORDS: Micronozzles, Micropropulsion, Microfabrication, Soft lithography

\section{INTRODUCTION}

Microsatellites $(<20 \mathrm{~kg})$ have provided the space community a low cost platform in performing space education and demonstration of new technologies in the last decade. The launching cost reduces significantly due to their small size and volume. Evolution of these satellites to perform actual scientific missions requires more pronouns manoeuvrability and fast response attitude control system for precise pointing and formation flying [1]. In order to fulfil the requirements of future missions, micropropulsion system with low thrust $(\mu \mathrm{N}$ to $\mathrm{mN})$, system mass $(<1 \mathrm{~kg})$, volume $\left(<1 \mathrm{~cm}^{3}\right)$ and power $(<1 \mathrm{~W})$ is required [2]. 
Previous numerical studies show that performance of micronozzle, a key component in micropropulsion system, is strongly affected by viscous effect [3, 4]. A deep micronozzle is preferred to mitigate viscous loss due to merging of viscous boundary layers at end walls. Aerospike micronozzle with virtual wall boundaries could further reduce viscous loss [5].

Deep reactive ion etching (DRIE), a proven but complicated technique in fabrication of micronozzles, would cause photomask breakdown over time and reduced wall straightness as the depth increases [6]. Moreover, the technique requires expensive equipments and tooling. In contrast, soft lithography, an inexpensive and relatively simple microstructures fabrication technique, enables fabrication of ultra-thick structure as thick as $1.5 \mathrm{~mm}$ with good vertical wall profile $[7,8]$.

In the present study, we first design two types of micronozzle, conical and aerospike, with the aim of improved efficiency through deep micronozzle approach. Micronozzles are then fabricated using soft lithography with PDMS as structural material. Surface contour and geometry accuracy of fabricated micronozzles are examined under inverted light microscope and scanning electron microscope (SEM).

\section{DESIGN OF MICRONOZZLES}

Designing micronozzles requires some unique considerations. Flow characteristics within micronozzles are different from their macro-scale counterparts. The flow is characterized by low Reynolds number, Re, where

$$
\operatorname{Re}=\frac{\rho V L}{\mu} \quad \text { or } \quad \operatorname{Re}=\frac{\dot{m} L}{\mu A}
$$

For a typical micronozzle operates at mass flow rate in the order of $\mu \mathrm{kg} / \mathrm{s}$ and characteristic length in $\mu \mathrm{m}$ scale, Re is within the range of $10^{1}$ to $10^{3}$ suggesting the significance of viscous effect and laminar flow behaviour [9]. Macro-nozzles experience small loss (less than $1 \%$ with occasionally up to $2 \%$ ) of total energy due to viscous effect [10]. Viscous boundary layer can occupy substantial portion of expander section causing a severe performance degradation in micronozzle. Traditional nozzle design approach based on inviscid flow theory is quite satisfactory in designing macro-nozzle but it is not totally applicable when designing micronozzles. However, inclusion of viscous effect would complicate the governing equations. In light of the complication, conventional quasi 1D inviscid theory was used as first approximation in current design. Important findings (e.g. larger micronozzle depth, shorter expander length etc.) from previous numerical studies on micronozzles were adapted into current design to mitigate viscous loss [3, 4]. Fabrication constraints inherited from available equipments were considered and relevant design limits were applied during the design process. Nozzle throat width, $w_{t}$, was limited to not smaller than $50 \mu \mathrm{m}$. Micronozzle depth was limited to $200 \mu \mathrm{m}$ after compromising between performance degradation due to 3D viscous effect and allowable nozzle throat width [4]. The $w_{t}$ was magnified by a factor of two in order to evaluate the fabrication capability while the nozzle depth was reduced accordingly to maintain a constant area of nozzle throat. 


\subsection{Conical Micronozzles}

Conical nozzles being the simplest nozzle shape are commonly used in micropropulsion system. Conical micronozzle with optimum expander half-angle demonstrates very similar performance in comparing with bell-shaped micronozzle [12]. Quasi 1D analysis [10] based on isentropic flow equations and rocket nozzle theory [13] were combined to evaluate for micronozzle design parameters such as micronozzle geometry and its internal flow characteristics. One of the most important parameters, nozzle expansion ratio, is formulated as

$$
\left(\frac{A_{e}}{A_{t}}\right)^{2}=\frac{1}{M_{e}^{2}}\left[\frac{2}{k+1}\left(1+\frac{k-1}{2} M_{e}^{2}\right)\right]^{\frac{k+1}{k-1}}
$$

The design parameters are summarized in Table 1. Conical micronozzles with expander half-angles, $\theta$, ranging from $10^{\circ}-50^{\circ}$ were designed. Details of the design process can be found in authors' previous work [11].

Table 1: Micronozzle design parameters.

\begin{tabular}{|c|c|c|c|}
\hline Design Input & Value & Design Output & Value \\
\hline Chamber pressure & $280 \mathrm{kPa}$ & Expansion ratio & 9.8 \\
\hline Chamber temperature & $513 \mathrm{~K}$ & Nozzle throat width & $\begin{array}{l}53.5 \mu \mathrm{m} \\
(107 \mu \mathrm{m})\end{array}$ \\
\hline Nozzle depth & $\begin{array}{c}200 \mu \mathrm{m} \\
(100 \mu \mathrm{m})\end{array}$ & Nozzle exit width & $522.7 \mu \mathrm{m}$ \\
\hline \multirow[t]{3}{*}{ Nozzle exit Mach no. } & 3.65 & Mass flow rate & $4.539 \times 10^{-6} \mathrm{~kg} / \mathrm{s}$ \\
\hline & & Specific impulse & $106.2878 \mathrm{~s}$ \\
\hline & & Throat Reynolds no. & 1207 \\
\hline
\end{tabular}

\subsection{Aerospike Micronozzles}

Aerospike nozzles were first investigated in early 1960s. The nozzle is characterized by no outer walls allowing exhaust gas to expand freely without constraining from walls. It is a promising candidate in achieving high performance propulsion system owing to this unique altitude compensation feature. Current aerospike micronozzles were designed with Angelino method (also known as Approximate method) [14]. The method combines Prandtl-Mayer expansion theory and area-Mach relation (equation 2) in determining spike geometry. Figure 1 shows a typical 2D aerospike nozzle. 


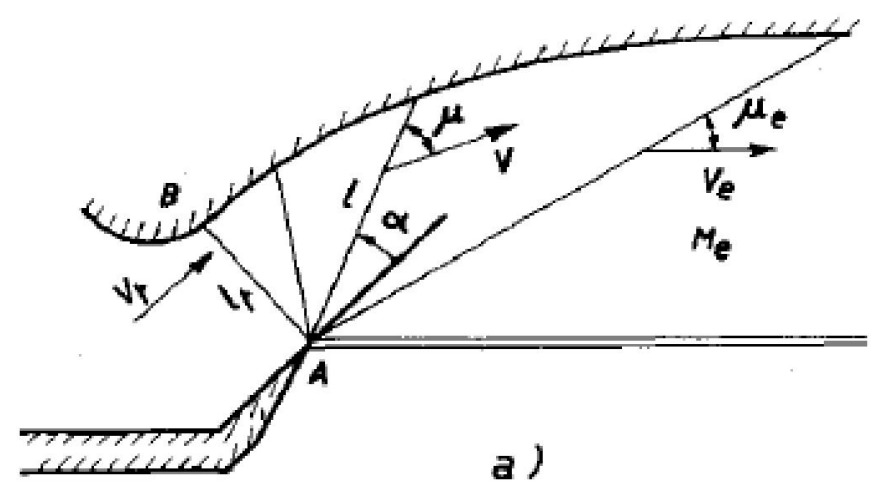

Fig. 1: Two dimensional aerospike nozzle [11].

Characteristic lines cross the nozzle boundary at distance $l$ from the lip, can be computed by

$$
l / l_{t}=(A / \sin \mu)\left(1 / A_{t}\right) \text { or } \quad \lambda=\varepsilon M
$$

where $\alpha=\mu(\mathrm{M})-v(\mathrm{M})$. Based on the same design parameters as conical micronozzles, length of the lines were calculated with equation (3) and converted into $\mathrm{X}$ and Y coordinates. Corresponding spike contour was plotted in Fig. 2.

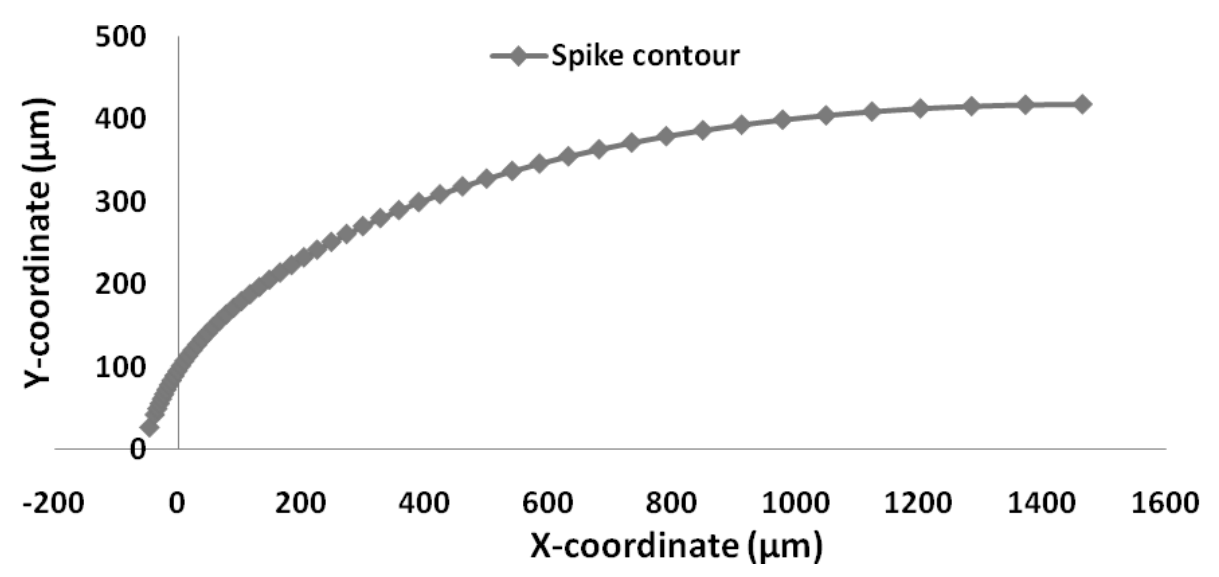

Fig. 2: Spike contour calculated with Angelino method.

\section{FABRICATION OF MICRONOZZLES}

\subsection{Materials}

In this study, a 5 inch silicon wafer (Shin-Etsu (M) Sdn. Bhd.) was used as substrate. SU-8 50 photoresist (PR) (MicroChem Corp.) and propylene-glycol-methyl-ether-acetate 
(PGMEA) were used as coating material and developer respectively. The designs were drawn using AutoCAD software and printed on a transparency film using a laser printer (EPSON T60) to generate a photomask. PDMS (Sylgard 184, Dow Corning) was used in replicating micronozzles from $\mathrm{SU}-8$ master.

\subsection{Methods}

The procedure of soft lithography is illustrated in Fig. 3 and described in detail below.

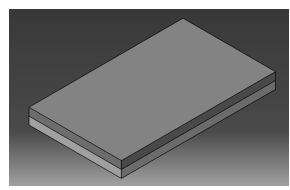

(a) Spin coating

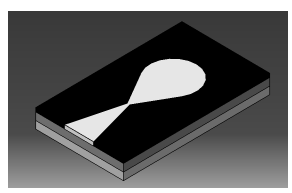

(b) Soft bake and exposure

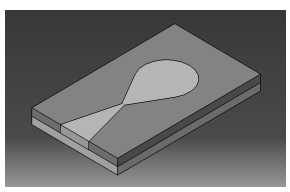

(c) Post-exposure bake

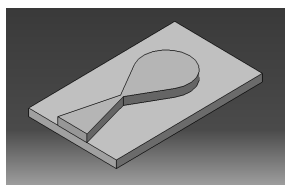

(d) PGMEA development

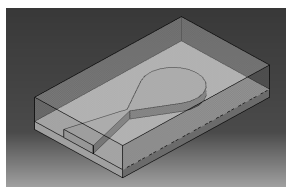

(e) PDMS molding

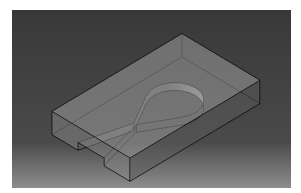

(f) PDMS peel off

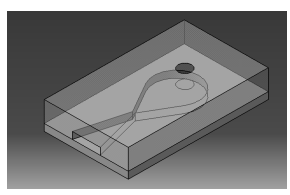

(g) Sealing

Fig. 3: Schematic of soft lithography in fabricating micronozzles.

\section{A. Master Preparation}

Prior to the process, silicon wafer was cleaned with standard RCA cleaning procedure followed by a pre-baked at $200^{\circ} \mathrm{C}$ for 5 minutes to remove any residual moisture on wafer surface [15]. About $5 \mathrm{ml}$ of SU-8 PR (1 ml per inch of wafer) was poured onto the wafer and slow spin at $500 \mathrm{rpm}$ for about 20 seconds to spread PR evenly. This was followed by a fast spin at $1250 \mathrm{rpm}$ for 30 seconds for a coating thickness of $100 \mu \mathrm{m}$. The spin coated wafer was then soft-baked at $65^{\circ} \mathrm{C}$ for 50 minutes. Soft-baking at lower temperature [16] would reduce stress-related crackings. Baking and cooling process were carried out at a slow rate $\left(5^{\circ} \mathrm{C} / \mathrm{min}\right)$ to avoid thermal stress. For coating thickness of $200 \mu \mathrm{m}$, the steps were repeated for additional $100 \mu \mathrm{m}$. The polymerization of SU-8 PR was assisted using self-customized UV-A radiation system (Philip TL-K 40W/10R) which radiates highly concentrated radiation between $350 \mathrm{~nm}$ and $390 \mathrm{~nm}$. Post-exposure bake was carried out at $55^{\circ} \mathrm{C}$ for 20 minutes with a ramping rate of $5{ }^{\circ} \mathrm{C} / \mathrm{min}$. After 1 hour of relaxation time, the wafer was immersed into PGMEA and agitated gently to dissolve the un-crosslink SU-8 PR. Developed wafer was silanized with 1,1,2,2 - tetrahydrooctyl-1-trichlorosilanem (UCT, Inc.) to facilitate mold release. The wafer with remaining patterns is known as SU8 master.

\section{B. Device Fabrication}

PDMS prepolymer was mixed thoroughly with its curing agent at 10:1 ratio by volume. The mixture was then placed into vacuum desiccators for degassing to remove 
bubbles introduced during mixing process. Degassed mixture was poured onto SU-8 master and cured at $65^{\circ} \mathrm{C}$ for 1 hour. PDMS device was then peeled off from the master.

\section{Device Sealing}

Fabricated PDMS device was sealed using hydrophilic bond. A piece of PDMS slide (cutting the leftover PDMS from previous steps into desired shape) and PDMS device was oxidized in freshly prepared strong oxidizing solution, a mixture of $98 \% \mathrm{H}_{2} \mathrm{SO}_{4}$ and $30 \%$ $\mathrm{H}_{2} \mathrm{O}_{2}$ at 1:1 ratio. The slide was dipped in the solution for 1 minute while the PDMS device for 15 seconds. Dipping for a longer time may damage the microstructures of the device. Both pieces of PDMS were rinsed with distilled water to remove residual acid and dried with compressed stream of air. The device was placed into contact with PDMS slide and heated at $70^{\circ} \mathrm{C}$ for 30 minutes.

\section{RESULTS AND DISCUSSION}

Figure 4 shows selected images of micronozzles printed on transparency film (mask) and their replication on PDMS. All images were investigated under inverted light microscope (Olympus, IX 51) with magnification of $40 \mathrm{X}$ and bright field mode. In general, all printed features can be distinguished clearly as micronozzles. The printer is capable in printing the smallest nozzle throat width of $53.5 \mu \mathrm{m}$ as nozzle throat was seen clearly and not filled by printer ink as shown in Fig. 4. Though, in comparison to $w_{t}=107$ $\mu \mathrm{m}$, the resolution is not satisfactory as micronozzle expander walls are not smooth in which some ripples were observed.

Images of PDMS micronozzles are shown below of each mask pattern for comparison. For $w_{t}=53.5 \mu \mathrm{m}$ and $\theta=10^{\circ}$, expander section of replicated micronozzle disintegrates from nozzle throat. The SU-8 structural strength is weak at smaller $w_{t}$, as shown in Fig. 5(a), crack was observed at nozzle throat. It is believed that the crack further propagates during thermal heating. Thermal stress is induced as a result of mismatch in thermal expansion coefficient of silicon and SU-8, leading to the disintegration. For $\theta=17.5^{\circ}$ and $w_{t}=53.5 \mu \mathrm{m}$, replicated nozzle loses its resolution, a narrow opening at nozzle throat which may retard or block the flow was observed. The resolution improves for $w_{t}=107 \mu \mathrm{m}$ as no potential flow blockage was observed and $w_{t}$ was found close to that in mask. Similar trend was observed for other expander angles. These results suggest $w_{t}=107 \mu \mathrm{m}$ is the more producible nozzle throat width with current equipments. It is supported by SEM images in Fig. 5(b) and (c), both conical micronozzles with $w_{t}=107 \mu \mathrm{m}$ show acceptable accuracy.

Current printing device is obviously lack of precision in printing full length spike geometry especially $w_{t}=53.5 \mu \mathrm{m}$. For $w_{t}=107 \mu \mathrm{m}$, geometry precision is acceptable up to $80 \%$ of total spike length. Images of PDMS aerospike micronozzle in Fig. 4 further justify the producible nozzle throat width is $107 \mu \mathrm{m}$ as blockage at nozzle throat was observed for $w_{t}=53.5 \mu \mathrm{m}$. Current equipments unable to produce spike contour with a sharp spike tip. As shown in Fig. 5(d), SU-8 near the sharp tip was not completely removed during the

development. As a consequence, the replicated spike tip for both $w_{t}$ are distorted as shown in Fig. 4. 

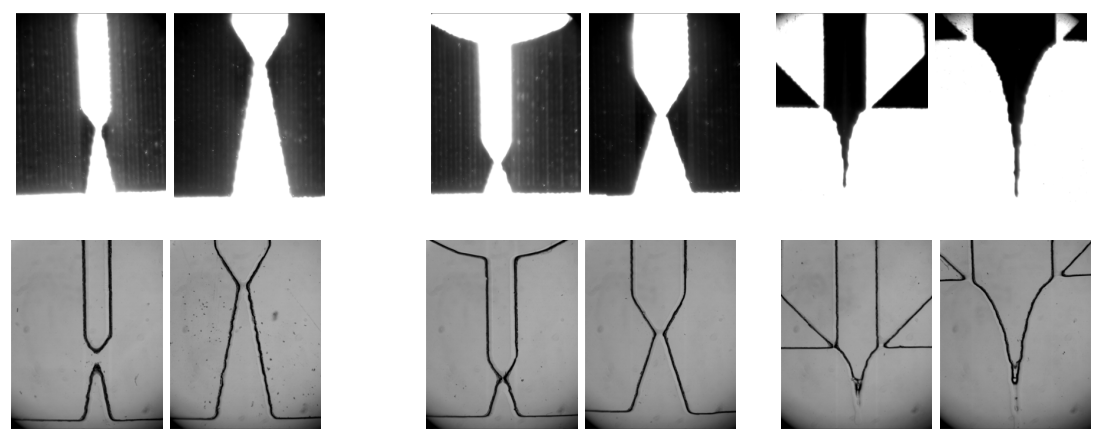

Fig. 4: Selected images of micronozzles (from left: conical $10^{\circ}$, conical $17.5^{\circ}$ and aerospike) with different nozzle throat width $(53.5 \mu \mathrm{m}$ and $107 \mu \mathrm{m})$ observed under inverted light microscope. First row is printed patterns on transparency film; second row is the replicated patterns on PDMS.

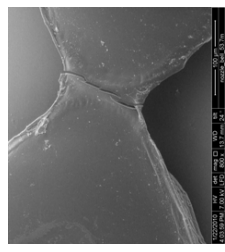

(a)

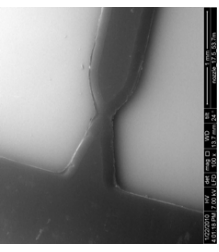

(b)

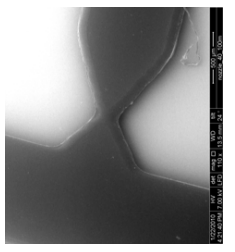

(c)

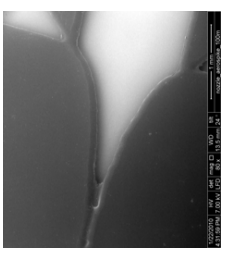

(d)

Fig. 5: SEM (FEI, Quanta400F) images: (a) crack at nozzle throat, $\theta=10^{\circ}, w_{t}=53.5 \mu \mathrm{m}$; (b) conical micronozzle, $\theta=17.5^{\circ}, w_{t}=107 \mu \mathrm{m}$; (c) conical micronozzle, $\theta=40^{\circ}, w_{t}=107 \mu \mathrm{m}$; (d) aerospike micronozzle, $w_{t}=107 \mu \mathrm{m}$.

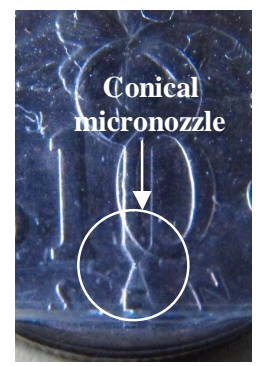

(a)

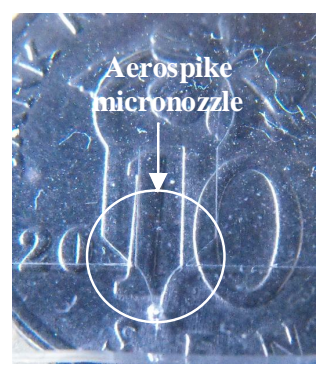

(b)

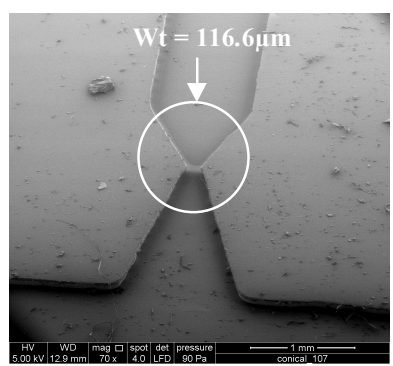

(c)

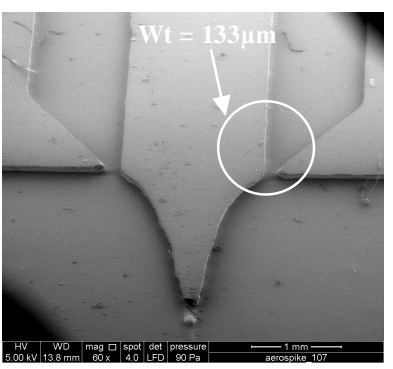

(d)

Fig. 6: Size of (a) PDMS conical micronozzle with $\theta=17.5^{\circ} w_{t}=107 \mu \mathrm{m}$; (b) PDMS aerospike micronozzle, $w_{t}=107 \mu \mathrm{m}$, compared with Malaysian 10 sen coin (dia. $\approx 1.9 \mathrm{~cm}$ ) and their SEM images in (c) and (d) respectively. 
Figure 6 (a) and (b) show photographs of PDMS micronozzles in comparison with a Malaysian 10 sen coin (diameter $\approx 1.9 \mathrm{~cm}$ ). Figure 6 (c) and (d) are SEM images of PDMS conical $\left(\theta=17.5^{\circ}\right.$ and $\left.w_{t}=107 \mu \mathrm{m}\right)$ and aerospike $\left(w_{t}=107 \mu \mathrm{m}\right)$ micronozzles. Measurements show conical micronozzle has $w_{t}=116.6 \mu \mathrm{m}$ while the aerospike micronozzle has $w_{t}=133.3$ $\mu \mathrm{m}$.

Further optimization on fabrication procedures is needed to improve wall smoothness and dimensional accuracy. Higher resolution mask is required in fabrication of micronozzles of smaller $w_{t}$. Truncated aerospike micronozzle should be considered as alternative if better photomask still cannot eliminate the spike tip problem.

\section{CONCLUSION}

In this research, we demonstrated that micronozzles can be fabricated through soft lithography. The technique is inexpensive and relative simple compared to wellestablished DRIE technique.

Conical and aerospike micronozzles were designed and fabricated in two different nozzle throat widths for comparison purpose. Microscopic inspections suggest $107 \mu \mathrm{m}$ is the more producible dimension with current equipments.

The potential application of PDMS-based micronozzle is limited to cold gas microthruster system due to relatively low decomposition temperature of PDMS. Future research would focus on fabrication optimization and the use of alternative structural materials such as ceramic which can work under high temperature.

\section{ACKNOWLEDGEMENT}

The authors would like to acknowledge MOSTI eScience Fund for funding the research.

\section{REFERENCES}

J. Mueller, C. Marrese, J. Polk, E-U. Yang, A. Green, V. White, D. Bame, I. Chakraborty and S. Vargo, "An Overview of MEMS-based micropropulsion development at JPL.", Acta Astronautica 52 (9-12): 881-895, 2003

R. Osiander, M.A. G. Darrin, and J.L. Champion, "MEMS and microstructures in aerospace applications.", CRC Press, US, 2006

W.F. Louisos and D.L. Hitt, "Viscous effects on performance of two-dimensional supersonic linear micronozzles.", Journal of Spacecraft and Rockets, Vol. 45, No. 4, 706715,2008

W.F. Louisos and D.L. Hitt,"Numerical studies of thrust production in 2D supersonic bell micronozzles.", $44^{\text {th }}$ AIAA/ASME/SAE/ASEE Joint Propulsion Conference \& Exhibit, 2008 
A. Zilic, D.L. Hitt and A.A. Alexeenko,"Numerical simulations of supersonic flow in a linear aerospike micronozzle.", $37^{\text {th }}$ AIAA Fluid Dynamics Conference \& Exhibit, 2007

R.L. Bayt, A.A. Ayon, and K.S. Breuer, "A Performance Evaluation of MEMS-based Micronozzles.", 33 ${ }^{\text {rd }}$ AIAA/ASME/SAE/ASEE Joint Propulsion Conf. \& Exhibit, 7-9 July, Seattle, WA, 1997

Y. Xia, and G.M. Whitesides, "Soft lithography", Annual Review of Material Science 28 (1): 153-184, 1998

C.H. Lin, G.B. Lee, B.W. Chang, and G.L. Chang, "A new fabrication process for ultra-thick microfluidic microstructures utilizing SU-8 PR.", Jour. of Micromech. and Microeng.12 (5), pp. 590-597, 2002

Louisos, W.F., Alexeenko, A.A. Hitt, D.L. and Zilic, A. (2008) Design considerations for supersonic micronozzles. International Journal of Manufacturing Research 3, no. 1: 80113.

G.P. Sutton, and O. Biblarz, "Rocket propulsion elements.”, 7th Edition, John Wiley \& Sons Inc, 2001

K.H. Cheah, J.K. Chin, and K.S. Koh, "Design and Performance Prediction of a $5 \mathrm{mN}$ HAN Monopropellant Microthruster", Int. Conf. on Mech. and Aero. Eng. 16-18 April, Chengdu, China, 2010

W.F. Louisos, and D.L. Hitt, "Numerical studies of thrust production in 2D supersonic bell micronozzles.", 44th AIAA/ASME/SAE/ASEE Joint Propulsion Conf. \& Exh., 21-23 July, Hartford, CT, 2008

J.D. Anderson, "Modern Compressible flow with historical perspective." 3rd Edition, New York: McGraw-Hill, 2003

G. Angelino, "Approximate method for plug nozzle design.”, AIAA Journal, Vol. 2 (10), 1834-1835, 1964

M. Bachman, "RCA-1 and RCA-2 silicon wafer cleaning.", INRF Application Note, 1999

T.A. Anhoj, A.M. Jorgensen, D.A. Zauner, and J. Hubner, "The effect of soft bake temperature on the polymerization of SU-8 photoresist." Journal of Micromechanics and Microengineering, 16, 1819-1824, 2006

\section{NOMENCLATURE}

$\begin{array}{ll}\mathrm{Re} & \begin{array}{l}\text { Reynolds number } \\ \text { nozzle exit area, } \mathrm{m}^{2}\end{array} \\ \mathrm{~A}_{\mathrm{e}} & \text { nozzle throat area, } \mathrm{m}^{2} \\ \mathrm{~A}_{\mathrm{t}} & \text { density, } \mathrm{kg} / \mathrm{m}^{3} \\ \rho & \text { characteristic length, } \mathrm{m} \\ \mathrm{L} & \text { flow velocity, } \mathrm{m} / \mathrm{s} \\ \mathrm{V} & \text { viscosity, } \mathrm{kg} / \mathrm{m}^{2} \mathrm{~s} \\ \mu & \text { mass flow rate }, \mathrm{kg} / \mathrm{s} \\ \dot{m} & \text { area, } \mathrm{m}^{2} \\ \mathrm{~A} & \end{array}$




$\begin{array}{ll}\mathrm{M} & \text { Mach number } \\ \mathrm{k} & \text { ratio of specific heats } \\ \alpha & \text { geometric angle with reference axis } \\ 1 & \text { length of characteristic segment, } \mathrm{m} \\ \lambda & 1 / \mathrm{l}_{\mathrm{t}}, \text { non-dimensional length for plane nozzle } \\ \varepsilon & \mathrm{A} / \mathrm{A}_{\mathrm{t}}, \text { expansion ratio } \\ \mathrm{W}_{\mathrm{t}} & \text { nozzle throat width } \\ \theta & \text { expander half-angle }\end{array}$

$\begin{array}{ll}B & \text { body force due to sediment particles } \\ C a & \text { cavitation number } \\ C_{D} & \text { drag coefficient } \\ \mathrm{C}_{\mu} & \text { anisotropic Diffusion Coefficient } \\ C_{s 1}, C_{s 2,} C_{1 \varepsilon,} C_{2 \varepsilon} & \text { RS Coefficients } \\ d_{p} & \text { particle diameter } \\ E & \text { erosion rate density } \\ F_{D} & \text { drag force } \\ \mathrm{F}_{\mathrm{cond}} & \text { cavitation condensation coefficient } \\ \mathrm{F}_{\mathrm{vap}} & \text { cavitation vaporization coefficient } \\ g & \text { gravitational acceleration of the sediment particles } \\ k & \text { erosion model constant } \\ \mathrm{p}_{\mathrm{v}} & \text { particle mass } \\ \mathrm{R}_{\mathrm{B}} & \text { velocity exponent } \\ \mathrm{P}_{\mathrm{s}} & \text { saturation pressure of water } \\ p & \text { fluid pressure } \\ & \text { vabour pressure } \\ & \end{array}$




$\begin{array}{ll}\mathrm{R}_{\mathrm{f}} & \begin{array}{l}\text { cavitation rate under relaxation factor } \\ r_{f} \\ \mathrm{r}_{\text {nuc }}\end{array} \\ r_{p} & \text { fluid phase volume fraction } \\ U_{c} & \text { particulate phase volume fraction } \\ U_{p} & \text { fluid velocity } \\ U & \text { particle velocity } \\ V_{p} & \text { particle relative velocity } \\ \end{array}$

\section{Greek letters}

$\beta$

particle mass loadings

$\gamma$

particle impact angle

$\rho_{f}$

fluid density

$\rho_{p}$

particle density

$\rho_{\mathrm{s}}$

nucleation site density

$\rho_{\mathrm{r}} \quad$ density ratio

$\sigma$

stress tensor

$\sigma_{\varepsilon}$

turbulence model constant

$\sigma_{\mathrm{k}}$

turbulence model constant for the k-equation

$\sigma_{\mathrm{t}}$

surface tension coefficient

$\tau_{p}$

particle response time

$\mu$

fluid dynamic viscosity

$v$

fluid kinematic viscosity 